\title{
Proceeding
}

Supplementary Issue: Summer Conferences of Sports Science. $8^{\text {th }}$ International Workshop and Conference of the International Society of Performance Analysis of Sport (ISPAS), 11-1 th of September 2019 (Budapest, Hungary) "Technology meets Practice and Science".

\section{The evaluation of the high peak of speed in footballers: Survey of all category from an amateur youth academy}

\author{
BERNARDO RICIOPPO ${ }^{1}$, CIRO HOSSEINI VARDE'I ${ }^{1}$, ANTONIO CEJUDO-PALOMO², RICCARDO IZZOำ \\ ${ }^{1}$ Department of Biomolecular Sciences, School of Sport Science, Exercise and Health, University of Urbino \\ Carlo Bo, Urbino, Italy \\ ${ }^{2}$ Department of Physical Activity and Sports, University of Murcia, Spain
}

\begin{abstract}
The analysis of youth football performance can help and increase the selection of talents and help coaches to work better during training, this can be possible with a multifactorial analysis of footballers using even specific hardware such as GPS, video-tracking and accelerometer. The aim of this study was to investigate the high peak speed (H.P.S) in youth football category and to determinate, how much times, footballers reach it during matches. Were analysed 120 athletes belonging to an amateur academy, 30 for each category $\mathrm{U}-12, \mathrm{U}-14, \mathrm{U}-16$ and $\mathrm{U}-18$. Was performed a sprint test on 30 meters in order to assess the average HPS, for each category from the academy, and in the end analyse how much the H.P.S is reached during one test match performed for every category. The sprint tests on 30 meters were performed using GPS $10 \mathrm{~Hz}$ (K-Sport Universal, Montelabbate, Italy), each athlete repeats the test 3 times the best performance was selected. The calculation of the average events for players during matches (AE-P) was calculated dividing the HPS events by the numbers of players (9 for U-12, 11 for U-14, U-16 and U-18). Results shows of events upper the H.P.S are growing exponentially by U-16 to U-18, with a difference of $72 \%$. The AE-P shows in average how much events are expected by players; no particular difference was showed from U-12 to U-16 (with a value starting from 0,5 and a maximum of 0,6 events). In the U-18 the events exponentially grow and reach the value of 1,3 . All the results let to assume that the maturation ratio in the academy, influence the variations and differences in the results. The analysing of the PPM even for young footballers can be the way to rationalize performance evaluation, as regards the study of H.P.S between category, it can provide useful information to evaluate, predict and help the talents research. Keywords: High peak of speed; Player performance model; Youth academy; Performance analysis; Speed trending.
\end{abstract}

Cite this article as:

Ricioppo, B., Varde'i, C.H., Cejudo-Palomo, A., \& Izzo, R. (2019). The evaluation of the high peak of speed in footballers: Survey of all category from an amateur youth academy. Journal of Human Sport and Exercise, 14(5proc), S2441-S2444. doi:https://doi.org/10.14198/ihse.2019.14.Proc5.60

Corresponding author. Department of Biomolecular Sciences, School of Sport Science, Exercise and Health, University of Urbino Carlo Bo, Urbino, Pesaro e Urbino 61029, Italy.

E-mail: riccardo.izzo@uniurb.it

Supplementary Issue: Summer Conferences of Sports Science. $8^{\text {th }}$ International Workshop and Conference of the International Society of Performance Analysis of Sport (ISPAS), 11-13 th of September 2019 (Budapest, Hungary).

JOURNAL OF HUMAN SPORT \& EXERCISE ISSN 1988-5202

(c) Faculty of Education. University of Alicante

doi:10.14198/jhse.2019.14.Proc5.60 


\section{INTRODUCTION}

The players performance model (PPM) consists of numerous components that go to compete to create the sport performance itself. The analysis of performance of youth football, could offer different insights to be able to select the talent or differentiate the training sessions. The aim of this study is to investigate the high peak speed in youth football category and to determinate, how much times, footballers reach this during matches. Other studies worked in sprint and high peak speed, but no one of this were investigate differences between all categories (Brownstein et al, 2018). Speed is the ability to make shifts as quickly as possible. This definition also implies the concept of rapidity, which is the ability to perform movements as quickly as possible. Ultimately, for speed we can understand the time taken to make a movement of the body, or of a segment, from a point $A$ to a point $B$, without the fatigue intervening; or the time taken to perform an exercise, be it cyclical or acyclic. Rapidity, on the other hand, implies the ability to reach, in the shortest possible time, the maximum speed of movement (for example, the speed of a defender in changing his direction of travel when he does not want to be overtaken by an attacker). Last but not least, it is important to underline the definition of the high-speed peak, that is the highest value of the instantaneous speed detected in a given time, in which, the instantaneous speed is defined as the limit of the average speed for intervals of very short time, that is the derivative of the position with respect to time. The growth of the human being in childhood passes through different stages, defined as sensitive phases that concern the period between 6 and 15 years, where certain motor skills and psychophysical qualities present a specific aptitude for improvement, because the organism is more predisposed to learn. As highlighted by Weineck (1996), in the footballer the speed capability contemplates different aspects, some of which are referable to cognitive-behavioural speed and are: Perceptual Speed, defined as the athlete's ability to be able to understand, from a technical point of view, a specific game action and be able to intervene in this context in a very short and effective time; Anticipation Speed, understood as the ability to sense and anticipate the action of the opponent; Reaction Speed, represented as the ability to react instantaneously to unpredictable actions. Another crucial capacity in football is the ability of repeat sprints during matches, as is known by literature is possible to increase with the use of specific trainings (Raiola et al., 2014, Vitale et al., 2018,) Preliminary study on effects of hit-high intensity intermittent training in youth soccer players, Journal of Physical Education and Sport, 14 (2), 148150.). Define a PPM for youth professional footballers, in order to compare and evaluate individual performance could help teams and coaches to select players (from an objective point of view) at least about physical performance, and can be a part of process in the evaluation, research and analysis of sports talent (Unnithan et al., 2012).

\section{METHODS}

Were analysed 120 athletes belonging to an amateur academy, 30 for each category U-12, U-14, U-16 and U-18. The aim of the survey was performing a sprint test on 30 meters in order to assess the average H.P.S, for each category from the academy, and in the end analyse how much the HPS is reached during one test match performed for every category. The sprint tests on 30 meters were performed using GPS $10 \mathrm{~Hz}$ (K-Sport Universal, Montelabbate, Italy), each athlete repeats the test 3 times (performing a pause of 2 minute between repetitions), only the best performance was selected. Is important to notice that in accordance with the reference coaches, all the athletes performed a rigorous and standardized warm-up. Was settled an average HPS for every category, based on data detected, subsequently for every category was analysed one match with the use of GPS (one for every players except for the goalkeeper) in order to discover if, and how much times, the HPS was reached and calculating the average events for players during matches (AEP) dividing the HPS events by the numbers of players (9 for U-12, 11 for U-14, U-16 and U-18). Data were 
processed with proprietary software (K-Fitness, K-Sport Universal, Montelabbate, PU, Italy) and then analysed with using spreadsheets (Excel, Microsoft, USA).

\section{DATA ANALYSIS AND DISCUSSION}

Data obtained from the sprint tests are showed in Table 1, H.P.S $(\mathrm{Km} / \mathrm{h})$ the S.D and the Max $(\mathrm{Km} / \mathrm{h})$ and Min $(\mathrm{Km} / \mathrm{h})$ values were calculated to better characterize and analyse the data obtained. The S.D shows that the deviation of the group was higher in the $U-14$ and lower in the $U-18$, this result could be connected with the state of maturation of athletes, that are more equalized more the age grows, as showed from our output data. The Max and Min data helps to understand the difference between the higher value from the lover, from $\mathrm{U}-12$ to $\mathrm{U}-16$ the differences between Max and Mix where important in average a 4,4 Km/h, in $\mathrm{U}-18$ the difference showed was significantly lower $2,3 \mathrm{Km} / \mathrm{h}$, no particular difference were detected between the Max value between U-16 and U-18 (respectively 29,7 and 29,8 ). The trend of the H.P.S between category show the growing of the speed during the different phases of evolution, analysing this using the percentage help to define the results: $8 \%$ between $U-12 / U-14,10 \%$ between $U-14 / U-16,3 \%$ between $U-16 / U-18$ and in the end from the first and last academy category $U-12 / U-18$ the difference detected was $20 \%$.

Table 1. Data obtained from Sprint Tests divided by category.

\begin{tabular}{ccccc}
\hline Category & H.P.S & S.D & Max & Min \\
\hline U-12 & 22.7 & 1 & 24.6 & 21.1 \\
U-14 & 24.7 & 1.3 & 28.1 & 22.7 \\
U-16 & 27.5 & 1.1 & 29.7 & 25.8 \\
U-18 & 28.4 & 0.6 & 29.8 & 27.5 \\
\hline
\end{tabular}

Table 2 shows the data obtained from the matches, category for category. Number of events upper the H.P.S are growing exponentially by U-16 to U-18, with a difference of $72 \%$, difference that are $0 \%$ between $U-14$ and $U-16$ and $40 \%$ from $U-12$ to $U-14$. The AE-P shows in average how much events are expected by players; no particular difference was showed from $U-12$ to $U-16$ (with a value starting from 0,5 and a maximum of 0,6 events). In the U-18 the events exponentially grow and reach the value of 1,3 .

Table 2. Data obtained from matches by category.

\begin{tabular}{ccc}
\hline Category & Events & AE-P \\
\hline U-12 & 3 & 0.5 \\
U-14 & 5 & 0.6 \\
U-16 & 5 & 0.5 \\
U-18 & 18 & 1.3 \\
\hline
\end{tabular}

\section{CONCLUSION}

The analysis of youth football performance can help and increase the selection of talents and help coaches to work better during training, this can be possible with a multifactorial analysis of footballers (Philippaerts et al., 2006). The use of new technology such as GPS, video-tracking and accelerometers can provide objective data, that can easily compare and evaluated during time. Data from survey shows us the H.P.S grows exponentially during maturation phases, the higher value is showed between U-14/U-16 with a $10 \%$, in the other end is important to notice how the lower S.D and lower the difference between Max and Min values are showed in the U-18 category, this is probably connected with the last phase of maturation that reduce the differences between the players. In total the growth between the first category analysed U-12 and the last U- 
18 are $20 \%$. Data obtained from the matches shows, how the growing of AE-P, between U-16 to U-18, are the higher, $72 \%$, that the difference between $U-14$ and $U-16$ are $0 \%$ and between $U-12$ to $U-14$ the difference was $40 \%$. In the U-18 the AE-P reach the value of 1,3 for matches. All the results let to assume that the maturation ratio in the academy, influence the variations and differences in the results. The analysing of the PPM even for young footballers can be the way to rationalize performance evaluation, as regards the study of H.P.S between category, it can provide useful information to evaluate, predict and help the talents research. What will therefore differentiate an amateur athlete from a professional will not be the maximum achievable speed value, but rather the ability to produce and high value of distance in sprint and to exceed the H.P.S threshold several times during matches (Izzo et al., 2018). Important approaches for future studies could be the possibility of being able to expand the aforementioned work on a larger sample collection, so as to be able to define, with greater precision, the different H.P.S for the various categories, thus increasing the reliability; moreover, it would be very interesting to be able to make a comparison between the data of the following study with those obtainable from youth sectors of elite teams (Izzo et al., 2019).

\section{REFERENCES}

Brownstein C.G., Ball D., Micklewright D. and Gibson N.V. (2018). The Effect of Maturation on Performance During Repeated Sprints With Self-Selected Versus Standardized Recovery Intervals in Youth Footballers. Pediatr Exerc Sci. Jul (22:1-6. https://doi.org/10.1123/pes.2017-0240

Gaetano, R., Rago, V. (2014). Preliminary study on effects of hiit-high intensity intermittent training in youth soccer players, Journal of Physical Education and Sport, 14 (2), 148-150.

Izzo, R., Franco, S., and Hosseini Varde'l, C. (2018). Analysis of Speed Thresholds in Youth Amateur Football Players Divided by Roles Using GPS Technologies. Journal of Sports Science, 6 (018) 246250. https://doi.org/10.17265/2332-7839/2018.04.004

Izzo, R., Varde'i, C.H., Raiola, G., \& Santinelli, F. (2019). Player Performance Model, comparison between youth professional (U-21) and professional first team football players: Different external load or not?. Journal of Human Sport and Exercise, 14(4proc), S991-S996. https://doi.org/10.14198/jhse.2019.14.proc4.61

Philippaerts R.M., Vaeyens R., Janssens M., Van Renterghem B., Matthys D., Craen R., Bourgois J., Vrijens J., Beunen G., Malina RM., (2006). The relationship between peak height velocity and physical performance in youth soccer players. Journal of Sport Sciences 24(3):221-30. https://doi.org/10.1080/02640410500189371

Unnithan V., White J., Georgiou A., Iga J. and Drust B. (2012. Talent identification in youth soccer. J Sports Sci. 30(15):1719-26. https://doi.org/10.1080/02640414.2012.731515

Vitale J.A., Povìa V., Vitale N.D., Bassani T., Lombardi G., Giacomelli L., Banfi G. and La Torre A. (2018). The effect of two different speed endurance training protocols on a multiple shuttle run performance in young elite male soccer players. Res Sports Med. Jul 4:1-14. https://doi.org/10.1080/15438627.2018.1492402

Weineck J. (1996). La preparazione fisica ottimale del calciatore. Calzetti Mariucci ISBN. 8886533136.

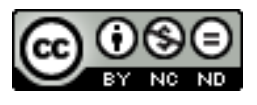

This work is licensed under a Attribution-NonCommercial-NoDerivatives 4.0 International (CC BY-NC-ND 4.0). 